\title{
Failed MitraClip procedure with pull out of the anterior leaflet
}

\author{
Susanne Rutschow*, Ursula Wilkenshoff, and Michael C. Gross \\ Department of Cardiology and Pulmology, Charite, Campus Benjamin Franklin, Hindenburgdamm 30, 12200 Berlin, \\ Germany \\ *Corresponding author's e-mail address: susanne.rutschow@charite.de
}

Published online: October 20, 2014 (version 1)

Cite as: Rutschow et al., ScienceOpen Research 2014 (DOI: 10.14293/S2199-1006.1.SORMED.AQBXG3.v1)

Reviewing status: Please note that this article is under continuous review. For the current reviewing status and the latest referee's comments please click here or scan the QR code at the end of this article.

Primary discipline: Medicine

Keywords: MitraClip, Dilated cardiomyopathy, Valve replacement

\begin{abstract}
MitraClip is an attractive and less invasive alternative to mitral valve surgery in serve mitral regurgitation in patients with moderate or severe risk for operation. It has been described to be effective and safe in functional as well as in degenerative mitral regurgitation. We report a case of MitraClip procedure with the pull out of the anterior leaflet during the intervention. The patient underwent cardiopulmonary support and surgical intervention with a good outcome. With this report, we illustrated the etiology and management of this complication.
\end{abstract}

\section{INTRODUCTION}

Mitral regurgitation in dilated cardiomyopathy is often a functional reason of either ischaemic or idiopathic origin. Furthermore, hybrid forms with functional as well as degenerative mitral regurgitation are described. Persistent severe mitral regurgitation leads to left ventricular and atrial chamber remodeling with poor clinical outcome [1]. In most patients, effective surgical repair of the mitral valve can cause decreasing in the left ventricular volume overload and can lead to reverse left ventricular and left atrial remodeling [2]. Mitral valve repair to reduce the mitral regurgitation by creating a double-orifice was first performed by Alfrieri [3]. Based on this surgical technique, endovascular mitral repair with the use of a clip has been developed [4]. Percutaneous mitral valve repair in edge-to-edge procedure with the MitraClip device has been shown to be associated with good clinical outcomes in patients with high risk for surgery [5]. Furthermore, it demonstrated to be superiorly safe compared with surgical mitral valve repair with similar improvement in clinical outcomes [6].

\section{CASE REPORT}

We describe a case of a 68-year-old man with severe mitral regurgitation and dilated cardiomyopathy with failed
MitraClip procedure. The medical history included inflammatory cardiomyopathy with initial highly reduced ejection fraction $(30 \%)$ by minor pronounced borderline myocarditis and normal coronary angiogram. With initiating of medical treatment, the left ventricle function was enhanced to $45 \%$ but was still persisting atrial fibrillation with unsuccessful cardioversion by severe mitral regurgitation with eccentric lateral jet. Furthermore, he had impaired renal function and a moderately combined lung disease (Euroscore 22\%). In cause of dyspnea by minimal stress, we decided to proceed with the procedure of MitraClip.

The preprocedural echocardiogram revealed minimal dilated left ventricle with end-diastolic dimension of $61 \mathrm{~mm}$ and moderate reduced left ventricular function with $45 \%$. We had a bi-atrial dilatation with $305 \mathrm{ml}$ for the left atrium and 144 $\mathrm{ml}$ for the right atrium with severe mitral regurgitation and moderate tricuspid regurgitation (Figure 1). The right ventricular systolic pressure was $40 \mathrm{mmHg}$ confirming pulmonary hypertension. The transesophageal echocardiogram conformed severe mitral regurgitation with eccentric lateral jet, posing a combination of degenerative and functional mitral regurgitation (Figure 2). With 3D-echocardiogram, we evaluated the possibility of MitraClip by enough leaflet substance without presentation of severe prolapse or structural disintegrity.

The standard procedure was performed with percutaneous femoral venous transseptal access. The clip was aligned above the mitral valve, approved with 3D-echocardiogram, before grasping and coapting the leaflets. The grasp of the leaflets was easy and unspectacular; with the second try of grasping, we demonstrated a reduction of the mitral regurgitation from severe to minimal, with remaining jet lateral of the clip. The verification of the leaflet insertion confirmed enough stuff of the posterior leaflet as well as of the anterior leaflet in the clip. By waiting 15-20 minutes after grasping and furthermore constant well-fitting clip, we decided a two-clip 


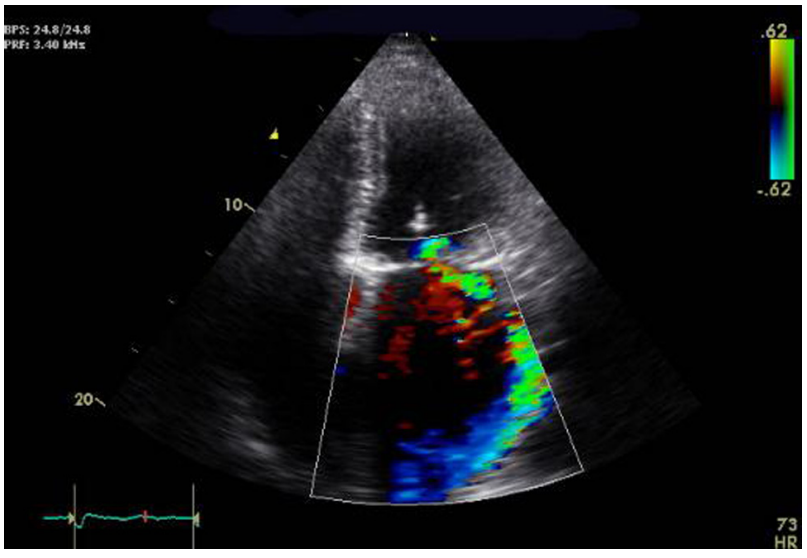

Figure 1. Preprocedural echocardiogram with bi-atrial dilatation.

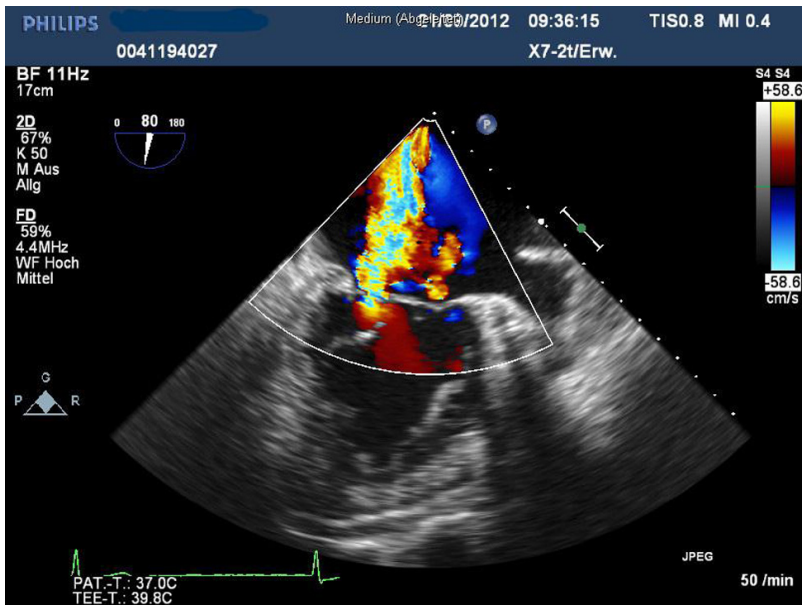

Figure 2. Preprocedural transesophageal echocardiogram with serve mitral regurgitation.

procedure to reduce the remaining lateral jet. After preparation of the second device transesophageal echocardiogram, it revealed a pull out of the anterior leaflet. The clip was only attached on the posterior leaflet. Out of the clip on the anterior side, we see approximately $8 \mathrm{~mm}$ stuff pull out of the anterior leaflet (Figure 3, Supplementary Video 1).

The procedure was discontinued and the anesthesia ended. The patient was awake and hemodynamic steady. Two days later, he received a standard median sternotomy with mitral valve replacement of a biological valve Labcor $31 \mathrm{~mm}$ (Figure 4). The postoperative process was prolonged in case of acute renal failure, sick sinus syndrome with the necessity of a permanent pacemaker, and infectious complications including a serve clostridia colitis. After six weeks of hospital stay, we could discharge the patient in rehabilitation.

Three months after mitral valve replacement in our outpatient department, the patient was obviously improved clinically. Echocardiogram revealed a good function of the mitral

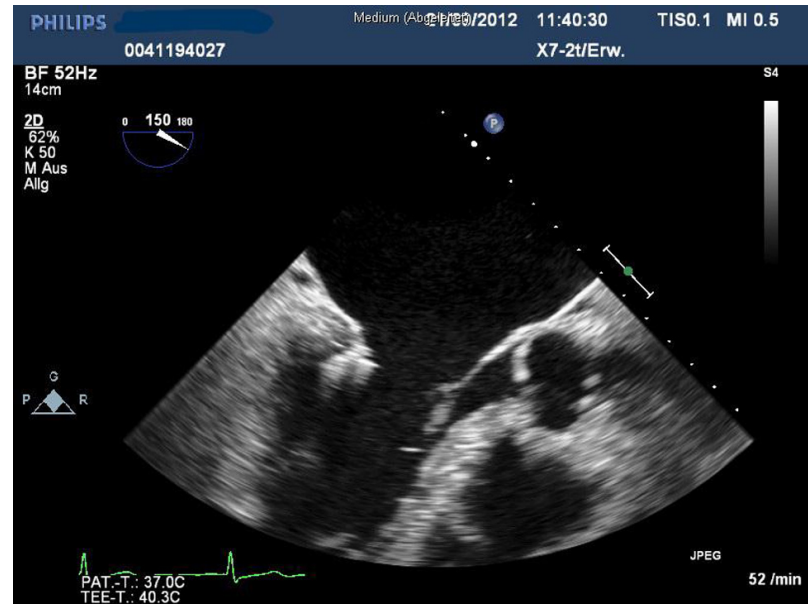

Figure 3. Intraprocedural transesophageal echocardiogram with pull out of the anterior leaflet.

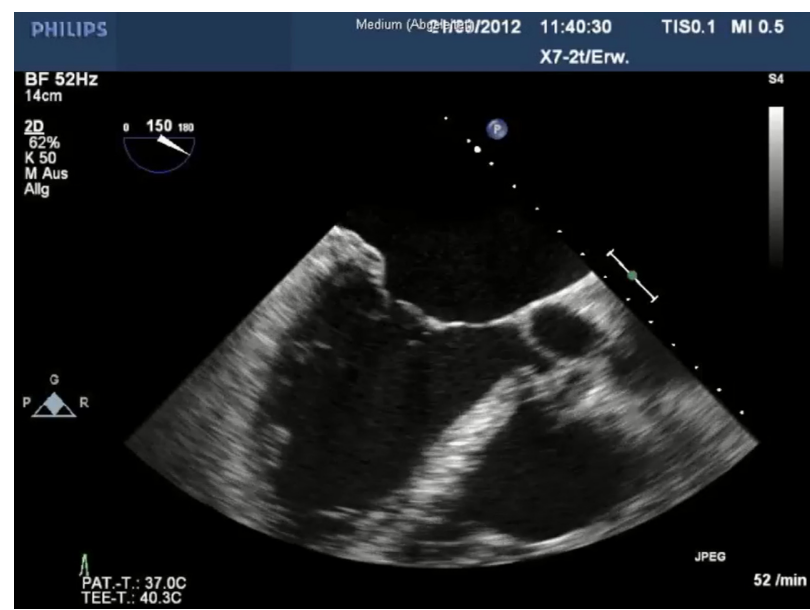

Supplementary Video 1. Trans-esophageal three chamber view with pull out of the anterior leaflet.

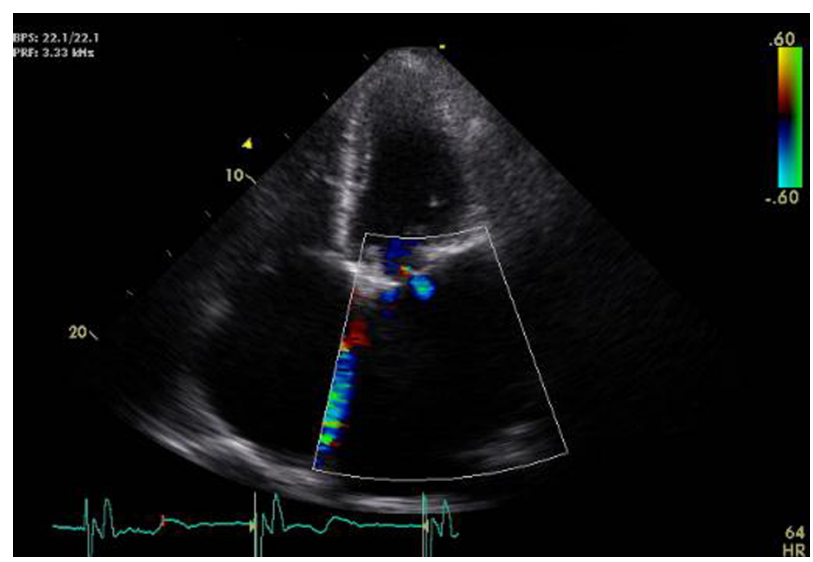

Figure 4. Postoperative echocardiogram with mitral valve replacement (Labcor $31 \mathrm{~mm}$ ). 
valve replacement without any mitral regurgitation by constant moderate tricuspid regurgitation.

\section{DISCUSSION}

Mitral clipping is an attractive alternative treatment of severe mitral regurgitation compared with cardiac surgery in patients with moderate and high risk for surgery. Described before is the dissolve of the posterior or anterior leaflet after insufficient leaflet insertion. This was the first report which shows the pull out of the anterior leaflet during the procedure. Beside the functional mitral regurgitation in cause of dilatation of the annulus, the MitraClip procedure is also described as effective and safe in degenerative mitral regurgitation. In spite of these observations, it might be necessary to have a careful analysis of the structural integrity of the leaflets in order to guard this situation, particularly in case of the missing possibility of mitral valve repair after MitraClip procedure as the first instance.

\section{REFERENCES}

[1] Trichon BH, Felker GM, Shaw LK, Cabell CH, O'Connor CM. Relation of frequency and severity of mitral regurgitation to survival among patients with left ventricular systolic dysfunction and heart failure. Am J Cardiol. 2003;91(5):538-43. doi:10.1016/ S0002-9149(02)03301-5

[2] De Bonis M, Lapenna E, Verzini A, IA Canna G, Grimaldi A, Torracca L, Maisano F, Alfieri O. Recurrence of mitral regurgitation parallels the absence of left ventricular reverse remodeling after mitral repair in advanced dilated cardiomyopathy. Ann Thorac Surg. 2008;85(3):932-39. doi:10.1016/j.athoracsur.2007. 11.021

[3] Alfrieri O, Maisano F, DeBonis M, Stefano PL, Torracca L, Oppizzi M, La Canna G. The double-orifice technique in mitral valve repair: a simple solution for complex problems. J Thorac Cardiovasc Surg. 2001;122(4):674-81. doi:10.1067/mtc.2001. 117277

[4] St Goar FG, James FI, Komtebedde J, Foster E, Oz MC, Fogarty TJ, Feldman T, Block PC. Endovascular edge-to-edge mitral valve repair: short-term results in a porcine model. Circulation. 2003; 108(16):1990-93. doi:10.1161/01.CIR.0000096052.78331.CA

[5] Whitlow PL, Feldman T, Pedersen WR, Lim DS, Kipperman R, Smalling R, Bajwa T, Herrmann HC, Lasala J, Maddux JT, Tuzcu M, Kapadia S, Trento A, Siegel RJ, Foster E, Glower D, Mauri L, Kar S. Acute and 12 month results with catheter-based mitral valve leaflet repair: the EVEREST II (Endovascular Valve Edge to Edge Repair) high risk study. J Am Coll Cardiol. 2012;59(2): 130-39. doi:10.1016/j.jacc.2011.08.067

[6] Feldman T, Foster E, Glower DG, Kar S, Rinaldi MJ, Fail PS, Smalling RW, Siegel R, Rose GA, Engeron E, Loghin C, Trento A, Skipper ER, Fudge T, Letsou GV, Massaro JM, Mauri L. EVEREST II Investigators. Percutaneous repair or surgery for mitral regurgitation. N Engl J Med. 2011;364(15):1395-406. doi:10.1056/ NEJMoa1009355

\section{COMPETING INTERESTS}

The authors declare no competing interests.

\section{PUBLISHING NOTES}

(C) 2014 S. Rutschow et al. This work has been published open access under Creative Commons Attribution License CC BY 4.0, which permits unrestricted use, distribution, and reproduction in any medium, provided the original work is properly cited. Conditions, terms of use and publishing policy can be found at www.scienceopen.com.

Please note that this article may not have been peer reviewed yet and is under continuous post-publication peer review. For the current reviewing status please click here or scan the QR code on the right.

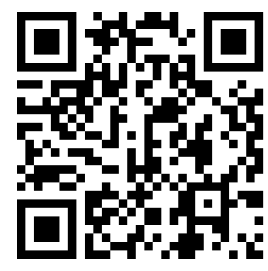

\section{scienceOPEN.com}

